\title{
REVISITANDO ALGUMAS TEORIAS DO \\ DESENVOLVIMENTO REGIONAL
}

Revising classical regional development theory

DOI: 10.48075/igepec.v25i1.25561

Nilton Marques Oliveira 


\title{
REVISITANDO ALGUMAS TEORIAS DO DESENVOLVIMENTO REGIONAL ${ }^{1}$
}

\author{
Revising classical regional development theories
}

DOI: $10.48075 /$ igepec.v25i1.25561

Nilton Marques Oliveira

\begin{abstract}
Resumo: O desenvolvimento regional constitui um processo de transformação social, econômica, cultural e política. Essas transformações são questões centrais para entender a evolução da dinâmica dos setores produtivos de uma região. Objetiva-se, neste texto, rever e analisar algumas teorias clássicas do desenvolvimento regional. Para tanto, utilizou-se de caráter reflexivo teórico-conceitual, fundamentado em uma revisão analítica da literatura. Um fato é concreto, o debate sobre desenvolvimento regional ganhou força, tendo sido estabelecidos um novo campo de pesquisa. Os principais resultados evidenciam que o desenvolvimento regional se dá de forma desigual no tempo e no espaço e, em pontos diferentes, com intensidades variáveis; expande-se por diversos canais e com efeitos sobre a economia local. A localização das atividades econômicas exerce, cada vez mais, influência determinante no desenvolvimento regional.
\end{abstract}

Palavras-Chave: Desenvolvimento regional; Polarização; Base econômica; Desigualdades regionais.

Abstract: Regional development is a process of social, economic, cultural and political transformation. These transformations are central issues to understand the evolution of the dynamics of the productive sectors of a region. This text aims to review and analyze some classic theories of regional development. For this purpose, a theoretical-conceptual reflective character was used based on an analytical review of the literature. One fact is concrete, the debate on regional development gained strength, and a new field of research was established. The main results show that regional development takes place unevenly in time and space and, at different points, with varying intensities; expands through several channels and with effects on the local economy. The location of economic activities is increasingly influencing regional development.

Key-words: Regional development; Polarization; Economic base; Regional inequalities.

Resumen : El desarrollo regional es un proceso de transformación social, económica, cultural y política. Estas transformaciones son cuestiones centrales para comprender la evolución de la dinámica de los sectores productivos de una región. El objetivo de este texto es revisar y analizar algunas teorías clásicas del desarrollo regional. Para ello, se utilizó un carácter reflexivo teórico-conceptual, basado en una revisión analítica de la literatura. Un hecho es concreto, el debate sobre el desarrollo regional ganó fuerza y se estableció un nuevo campo de investigación. Los principales resultados muestran que el desarrollo regional tiene lugar de manera desigual en el tiempo y el espacio y, en diferentes puntos, con intensidades variables; se expande a través de varios canales y con efectos en la economía local. La localización de las actividades económicas ejerce, cada vez más influencia determinante en el desarrollo regional.

Palabras-clave: Desarrollo regional; Polarización; Base económica; Desigualdades regionales.

1 Uma primeira versão deste texto foi apresentado no IX Seminário Internacional sobre Desenvolvimento Regional, realizado na Universidade de Santa Cruz - RS (UNISC) entre 11 e 13 de setembro de 2019. 
Informe GEPEC, ISSN:1679-415X, Toledo, v. 25, n.1, p. 203-219, jan./jun. 2021. 


\section{INTRODUÇÃO}

Nos anos 1950 e 1960, o debate sobre o desenvolvimento regional recebeu influência direta das chamadas teorias do desenvolvimento econômico, surgindo um novo debate: como as nações podem lançar mão de mecanismos para superar a pobreza (pós-guerra) e alcançar o desenvolvimento econômico? Várias teorias surgiram nesse período tendo como base o crescimento e o desenvolvimento econômico. Assim, diversos teóricos se propuseram a estudar a dinâmica regional com o propósito de esclarecer sua problemática, indicando soluções para a superação do atraso.

Entre estes teóricos, pode-se destacar François Perroux, cuja análise estimulou uma série de estudos convergentes como aqueles desenvolvidos por Jacques- $\mathrm{R}$ Boudeville, Gunnar Myrdal, Albert O. Hirschman e Douglass C. North. Em torno do pensamento destes estudiosos, foi estabelecido um consenso que passou a influenciar significativamente a condução da política econômica para a Europa e o resto do mundo (BRANDÃO, 2004; LIMA E SIMÕES, 2010). Estes teóricos procuraram demonstrar que uma vez estabelecidas as vantagens ou desvantagens comparativas dos espaços econômicos, são iniciados movimentos migratórios do capital, cujos resultados serão expressos em determinada dinâmica regional, isto é, em relativo vigor ou estagnação do processo de acumulação em uma região.

Uma das primeiras intervenções no processo de desenvolvimento regional foi a "Tennessee Valley Authority" ${ }^{2}$ e, bem mais tarde, em 1960, os polos de desenvolvimento e de crescimento e, em seguida, os Complexos Industriais, que serviram de inspiração e mesmo de paradigmas para as políticas de desenvolvimento regional. A partir de então, a miragem tem sido o "Silicon Valley", onde a noção de Sistemas (Arranjos) Produtivos Locais vem servindo de inspiração para a intervenção espacial em diferentes regiões (NETTO, 2019).

O objetivo deste trabalho é proceder a uma revisão das principais teorias do desenvolvimento regional, já revisitado por diversos autores. Faz-se mister considerar que os estudos sobre o desenvolvimento regional devem ser analisados sob múltiplos olhares, como, por exemplo, quando se procura compreender as relações entre espaços. A contribuição deste trabalho é resgatar essas teorias que vêm dando suporte teórico e metodológico às diversas dissertações e teses nos programas de pósgraduação. Este trabalho se utiliza de um ferramental metodológico exploratório, à guisa da literatura, entendido como procedimento de reflexão e análise necessária para o entendimento do desenvolvimento regional.

A desigualdade regional é identificada como a principal responsável por uma série de efeitos nocivos ao desenvolvimento socioeconômicos no âmbito das regiões econômicas desenvolvidas e em desenvolvimento. As distorções espaciais são ocasionadas pela ausência de políticas e/ou potencialidades econômicas naturais, diante de um forte processo de desajuste estrutural nos espaços econômicos.

Assim, os estudos das disparidades econômicas têm o fito de identificar e, posteriormente, propor políticas de redução das desigualdades com a promoção do desenvolvimento em função do incentivo à dinâmica produtiva nos espaços econômicos. Desenvolvimento regional compreende uma análise de fatores sociais e econômicos no interior de uma região, fatores esses que compõem a mobilidade espacial do capital, do trabalho e das inovações. Tais fatores, quando bem empregados em uma determinada região, podem reduzir ou acelerar as desigualdades regionais. $\mathrm{O}$ desenvolvimento regional constitui um processo de transformação social, econômico,

${ }^{2} \mathrm{O}$ “Tennesse Valley Authority” foi criado em maio de 1933 pelo governo federal norte-americano.

Informe GEPEC, ISSN:1679-415X, Toledo, v. 25, n.1, p. 203-219, jan./jun. 2021. 
cultural e político. Essas transformações são questões centrais para se entender a evolução da dinâmica dos setores produtivos de uma região (PERROUX, 1955; MYRDAL, 1968; BOUDEVILLE, 1973; ISARD, 1962; CHRISTALLER, 1933; RICHARDSON, 1975).

Isto posto, este artigo está divido em três seções, além desta introdução. A segunda seção apresenta a revisão das teorias que abordam as questões do desenvolvimento regional, incluindo a teoria dos lugares centrais, teoria da causação circular e efeito de encadeamento e a teoria da base econômica. As considerações finais sumarizam o artigo.

\section{DESENVOLVIMENTO REGIONAL: ALGUMAS CONSIDERAÇÕES}

O interesse pelo desenvolvimento regional por meio do estudo da organização da sociedade em termos espaciais data de muito longe3, embora nem todos os economistas lhe tenham atribuído a relevância merecida. Os estudos sistemáticos de base regional tiveram mais destaque no pós-guerra (1950). O debate nesse momento não se centrava mais no crescimento econômico, no PIB per capita, mas se voltava para um novo paradigma de qualidade de vida e bem-estar, esse novo debate se assentando em conceitos de desenvolvimento de forma holística, não apenas de crescimento.

O desenvolvimento regional será o fio condutor de orientação da necessidade de elaborar políticas e formular planos que as programem em suas devidas proporções, levando em consideração as características como as regiões se apresentam, sejam elas subdesenvolvidas, deprimidas ou congestionadas 4 .

Autores como Boisier (2000) e Furtado (2009) sugerem que o desenvolvimento regional seja impulsionado por uma política de Estado, juntamente com a sociedade civil organizada, tendo o planejamento como elemento chave nas proposituras das políticas regionais de desenvolvimento, levando em conta sua especialidade geográfica, a pressão populacional sobre os recursos naturais, sua organização social, estruturas religiosas, mentais e culturais. Além disso, leva-se em conta seu processo histórico de produção e de consumo.

Atribui-se, assim, grande importância à autonomia na capacidade de decisão, sem a qual não pode haver uma autêntica política de desenvolvimento. E como o principal centro de decisões é o Estado, atribui-se a ele um papel básico na consecução do desenvolvimento, mas, sobretudo, assevera Furtado (2009), que o desenvolvimento somente se realizará se forem criadas condições para uma participação ampla em seus frutos das massas urbanas e rurais (FURTADO, 2009).

A definição de desenvolvimento regional é em si multi e interdisciplinar. A concepção do desenvolvimento remonta ao início dos anos 6o, com os estudos de Perroux (1955). Para ele, o desenvolvimento era uma mudança social e mental que conduzia ao crescimento econômico e a melhorias nas condições de vida (PERROUX, 1955). Essa concepção chamou a atenção para a necessidade de estudos que envolvessem a abordagem de desenvolvimento numa dimensão mais abrangente, mais sistêmica, com outras concepções. Assim, na evolução econômica espacial das teorias

\footnotetext{
3 Um precursor muito esquecido foi Cantillon (1755), economista que desenvolveu questões sobre a teoria econômica, como a do valor, preço, comércio entre as nações, e sobre desenvolvimento.

4 Pode-se entender por subdesenvolvida a região que não criou meios que permitissem transformar suas estruturas para participar dos processos modernos de desenvolvimento urbano-industrial. Região deprimida é aquela que já teve alguma transformação, mas por ora atravessa uma fase difícil de transformação. Regiões congestionadas são aquelas que estão saturadas na utilização de seus recursos, apresentando grau de elevada concentração urbano-industrial.
}

Informe GEPEC, ISSN:1679-415X, Toledo, v. 25, n.1, p. 203-219, jan./jun. 2021. 
do desenvolvimento econômico e das próprias ciências sociais, surgiu a concepção de ciência regional (FERRERA DE LIMA, 2010).

Aydalot (1985) assegura que a abordagem do desenvolvimento regional deve ser realizada por estudos empíricos, a fim de identificar problemas específicos e diferenciados, exigindo, portanto, planejamento. Uma região tem sido definida por sua estrutura econômica, se caracterizando pelo maior ou menor dinamismo de crescimento. Áreas dinâmicas tendem a atrair fatores de produção e a crescer ainda mais rapidamente, enquanto regiões com problemas estruturais perdem populações e capitais (LOPES, 1984; FERRERA DE LIMA, 2010).

Lopes (1984) discute a problemática de conceituar e operacionalizar as políticas de desenvolvimento regional. De natureza conceitual, há três tipos de problemas a serem considerados: i) problemas de consideração da variável espaço; ii) problemas de interdependência regional e iii) problemas de abordagem pluridisciplinares. O planejamento surge como um conjunto de ações programadas no tempo em que se busca identificar os problemas regionais. Desse modo, na problemática do desenvolvimento regional, a análise, a política e o planejamento devem ser bem demarcados, definidos, pois o planejamento quase tende a se confundir com o desenvolvimento regional.

As regiões novas crescem quando crescem as demandas das demais regiões pelos seus produtos, provenientes das empresas localizadas no seu território. Com isso, a integração de uma região só pode ser compreendida quando analisados o perfil e a difusão das atividades de base no espaço territorial, o que estimula a inserção da economia regional na economia nacional. North (1977a) discute que o desenvolvimento regional passa num primeiro momento pela base econômica. $\mathrm{O}$ crescimento de uma região decorre do aumento das atividades de base econômica e, consequentemente, da demanda por produtos que ela oferece para fora da região. Crescendo e expandindo as atividades de base, cresce toda a economia regional.

A Figura 1 descreve os caminhos do desenvolvimento regional, mostrando o processo de elaboração por fases e com características de atividade cíclica e permanente. Esse processo exige análise, intervenção por meio das instituições e avaliação para seleção das políticas que conduzem aos planos de políticas de desenvolvimento.

Figura 1 - A Problemática do Desenvolvimento Regional

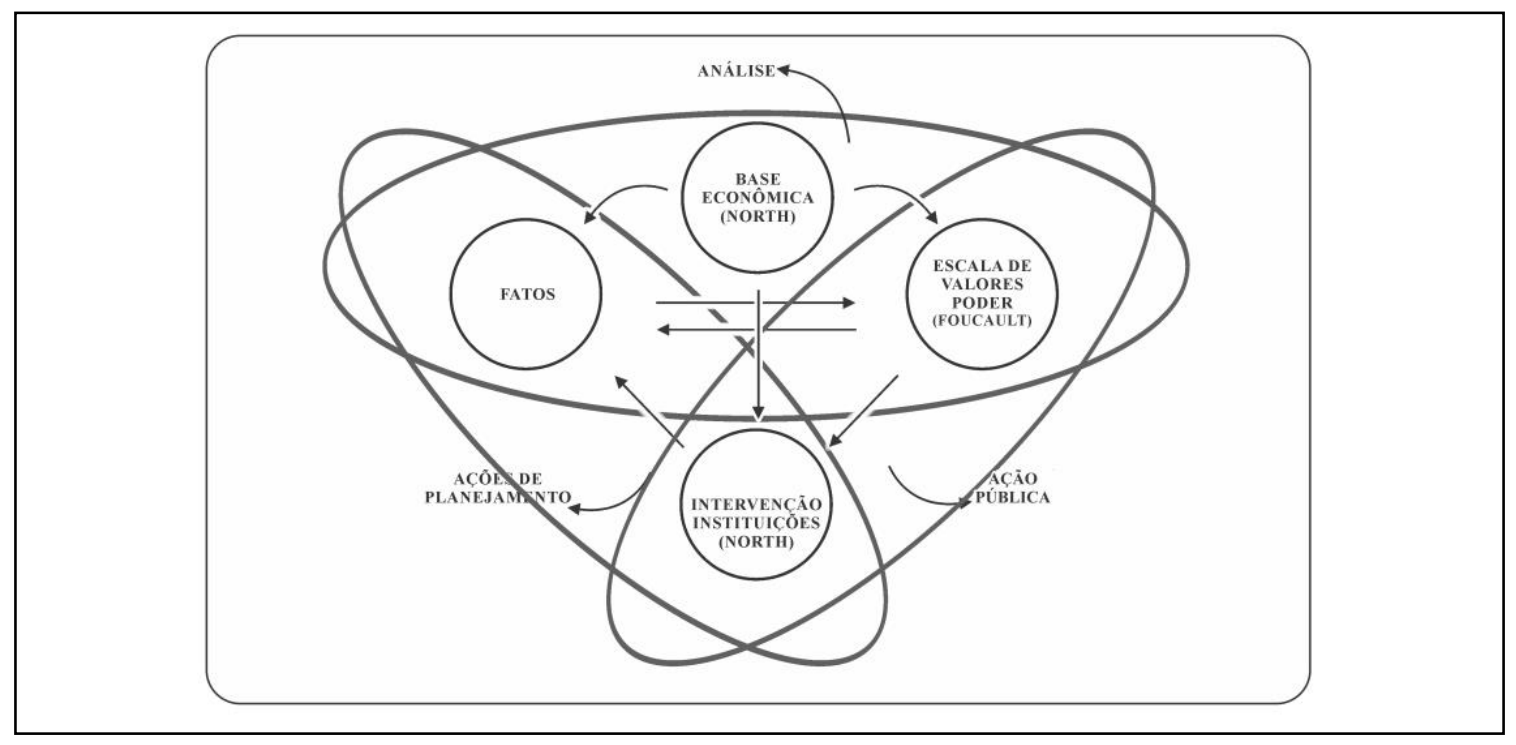

Fonte: Lopes (1984), adaptado pelo autor. 
Segundo Lopes (1984), o planejamento regional apresenta três tipos de limitações básicas: i) reduzido nível de integração entre os atores institucionais envolvendo o local e o setorial; ii) natureza técnica com reduzida flexibilidade dos planos regionais; e iii) delimitação da região prioritária. Essas limitações apresentadas por Lopes (1984) tendem a ser superadas na concepção de Boisier (1996, 2000), quando ele define que o desenvolvimento regional consiste em um processo de troca estrutural localizada, em âmbito territorial denominado região, que se associa a um permanente processo de progresso na própria região, na comunidade ou na sociedade onde habitam seus cidadãos.

Boisier (2000) se depara também com a complexidade do conceito de desenvolvimento regional. Devem, portanto, ser combinadas três dimensões: i) uma dimensão espacial, ii) uma dimensão social e iii) uma dimensão individual. O sucesso da região deve ser entendido com uma transformação sistemática entre essas três dimensões. Becker (2000, 2010) diz que o desenvolvimento regional contemporâneo passa por estes questionamentos: por que algumas regiões conseguem responder positiva e ativamente aos desafios regionais da globalização contemporânea, construindo seus modelos de desenvolvimento e outras não? Por que os processos regionais de desenvolvimento não são iguais dinamicamente e se diferenciam entre si?

A resposta estaria na seguinte pressuposição:

Teoricamente, entretanto, devemos partir do pressuposto de que o desenvolvimento capitalista é a própira contradição em processo, pois se move constatemente em meio a contradições superadas, porém postas e respostas continuamente pelo próprio capital, através da negação das suas próprias determinações (BECKER, 2010, p. 38).

Em outras palavras, o capital nega a determinação humana do desenvolvimento, transformando o trabalho humano na mercadoria mão de obra, transformando a natureza em matéria-prima, que se transforma em mercadoria, dinheiro e, dessa forma nega, sua própria negação, ao transformar mercadorias em capital (BECKER, 2010).

Para Matos (2000), os modelos de desenvolvimento regional se assentam em dois pilares: um funcional e outro territorial. No primeiro, o desenvolvimento é funcional, seu motor é o progresso técnico, e o território é considerado o espaço em que a atividade econômica se desenvolve. No segundo, o território é um elemento ativo que influencia o desenvolvimento da região. Nesta perspectiva, o desenvolvimento regional terá lugar em razão de uma conjugação de fatores internos 5 (STÖHR, 1981) e de fatores externos ${ }^{6}$, (MARSHALL, 1890). Importante observar que os estudos das desigualdades regionais sempre foram assunto dos primeiros estudiosos da economia regional. A premissa de que o desenvolvimento não ocorre de forma homogênea entre as diferentes regiões era compartilhada por todos, entretanto, divergindo quanto aos efeitos da polarização.

Reigado (2000) advoga que desigualdades regionais são produto do mapa mental dos atores sociais e econômicos, isto é, a imagem subjetiva do conhecimento espacial como um fator importante na escolha da localização ótima não só pelos

5 Os fatores internos ou endógenos referem-se à capacidade de organização local, definida como capital social, que é um dos elementos que compõem o desenvolvimento regional.

${ }^{6}$ Os fatores externos que geram externalidades positivas são: i) a possibilidade de uma atividade produtiva obter mão de obra especializada e a um menor custo em regiões em que haja concentração de outras atividades; ii) a compra de matérias-primas poderá ser facilitada pela proximidade com os fornecedores; e iii) localizar-se próximo a outras atividades facilitaria a dispersão de informações.

Informe GEPEC, ISSN:1679-415X, Toledo, v. 25, n.1, p. 203-219, jan./jun. 2021. 
consumidores, mas também pelos produtores. Os agentes econômicos agem na fronteira da racionalidade econômica, pelo que suas escolhas quase sempre se dão de forma probabilística.

A localização das atividades econômicas exerce, cada vez mais, influência determinante no desenvolvimento regional. Os modelos de localização foram iniciados por von Thünen (1826), na Alemanha, com seu estudo sobre produção agrícola, e tinham por objetivo explicar o padrão de localização da agricultura alemã, tendo procurado demonstrar que ela decorria da combinação da produtividade física da terra com a distância aos mercados e os custos de transporte, que determinavam os anéis de especialização agrícola.

Dando sequência à revisão de literatura, a seguir são apresentadas algumas considerações sobre a teoria dos lugares centrais, teoria da causação circular e efeito de encadeamento e, por fim, a teoria da base econômica.

\subsection{TEORIA DOS LUGARES CENTRAIS}

Essa teoria tenta justificar o número de centros, a dimessão e sua distribuição espacial, fazendo-o tendo como apoio os princípios clássicos da oferta e da procura, em que a ideia de maximização do lucro (por parte do ofertante) se coaduna com a ideia de minimização do esforço (por parte do demandante) de bens e serviços. É a partir disto que os dois conceitos básicos de sua teoria são apresentados: limiar da procura, o mínimo de procura que justifica a iniciativa da oferta; e o limiar de alcance do bem, a distância e o custo máximo que o comprador está disposto a arcar para adquirir algo (LOPES, 1984).

A teoria está baseada nas seguintes hipóteses e pressupostos: 1) a população está distribuída no espaço de forma homogênea, considerando-o isotrópico, isto é, a ocupação humana seguiria um padrão triangular para permitir que as distâncias sejam parecidas entre os demandantes; 2) a oferta se localiza espacialmente num sistema de pontos, os lugares centrais; 3) a demanda de bens e serviços nesses pontos é assegurada pela população que neles reside e pela região complementar; 4) a ordem dos bens e serviços oferecidos num centro está em associação com a própria ordem de importância do centro, cuja medida é o conceito de centralidade; e 5) um centro que desempenha funções de ordem superior também desempenha funções de ordem inferior (CHRISTALLER, 1933). A teoria dos Lugares Centrais se fundamentava na análise das estruturas de centros do Sul da Alemanhã, cuja centralidade foi determinada utilizando um índice calculado com base na utilização do telefone, classificando cada centro em níveis de influência hierarquica.

Oliveira (2019), por sua vez, apresenta que, por esta teoria, o desenvolvimento e o crescimento das áreas urbanas dependeriam do tipo de serviço fornecido ao seu entorno. A hierarquia destas aglomerações urbanas é definida pela influência de cada um sobre o outro. Quanto maior a centralidade, maior a influência exercida pelo centro.

O mesmo autor também afirma que a centralidade também apresentaria o padrão da formação das redes de cidades e o papel que cada uma desepenha nela, de tal forma que quanto maior sua área de influência, maior sua polarização, conforme pode ser mais bem visualizado na Figura 2. A densidade populacional de renda ou do número de atividades produtivas será a responsável pelo desenvolvimento dos lugares centrais, em especial do setor terciário, que serve de indicador natural da capacidade de polarização, uma vez ser ele dependente dos dois setores anteriores (primário e secundário) (OLIVEIRA, 2019). 
O setor terciário, para tanto, é o compositor das funções do lugar central, isto é, os diversos tipos de comércio e serviços, desde os públicos até os privados, especializados, pequenos ou grandes, religiosos ou seculares, saúde, educação etc. $\mathrm{O}$ lugar central é dado pela relevância de um determinado bem ou serviço ofertado, por conseguinte, organizado segundo as funções desempenhadas, quanto maiores, seriam também sua escala hierárquica (OLIVEIRA; BRITO; MEDEIROS, 2013). Dois conceitos também importantes a ser apresentados são o de alcance espacial mínimo (minimum range threshold) e o de alcance espacial máximo (maximum range). $\mathrm{O}$ primeiro diz respeito à área do seu entorno; o segundo trata da abrangência de determinado lugar central em atrair consumidores em um determinado raio. Cabe ressaltar que a teoria dos lugares centrais entendia que todo núcleo de povoamento é encarado como lugar central, uma vez fornecedor de bens e serviços, desconsiderando, inclusive, seu tamanho (OLIVEIRA; BRITO; MEDEIROS, 2013).

O conceito utilizado nesta pesquisa não é somente o de distância geográfica, mas também o de distância econômica, que leva em consideração o custo do frete e o seguro, o transporte, a armazenagem, a embalagem e o tempo necessário para chegar até o local (ALMEIDA; ARAÚJO; RODRIGUES, 2009). A hierarquia entre os centros é associada aos bens e serviços oferecidos, e os consumidores levariam sua demanda até o centro mais próximo onde eles fossem oferecidos, de tal forma que os centros de ordem superior se sobressaem sobre os demais nos fatores atrativos (MONASTERIO; CALVACANTE, 2011).

$\mathrm{Na}$ Figura 2, cada ponto representa um lugar central. Estes pontos se escalonam em nível hierárquico dos menores, os centros $\mathrm{M}$, aos maiores, os centros $\mathrm{G}$, de tal modo a formar uma rede hierárquica entre os centros, dada a capacidade que os centros superiores têm de atrair os inferiores.

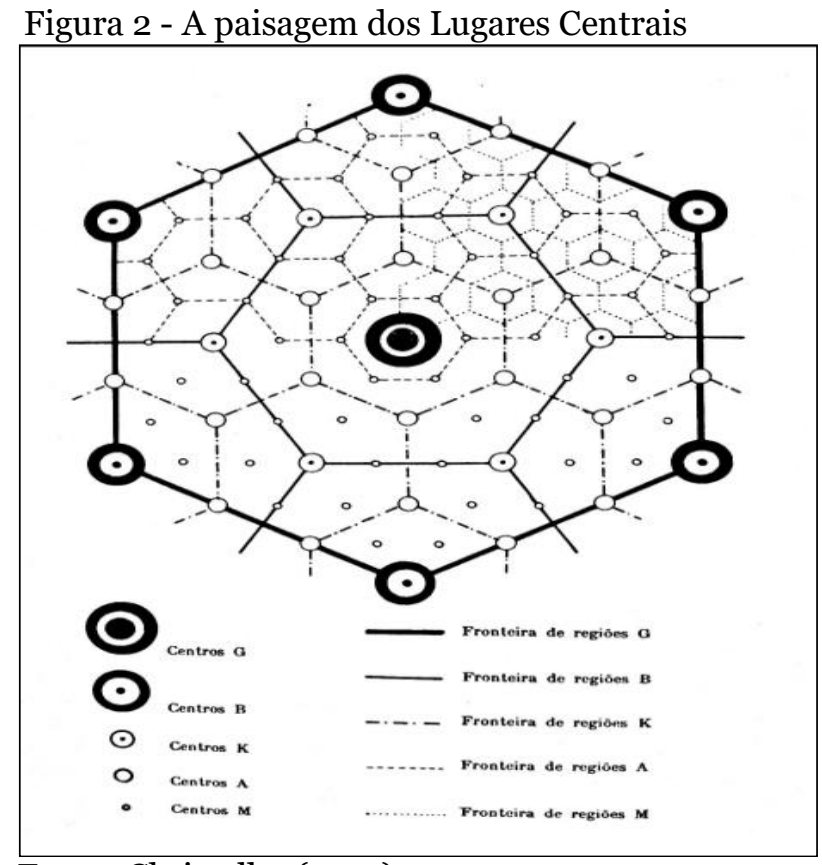

Fonte: Christaller (1933).

A teoria dos lugares centrais também é definida segundo três princípios pelos quais seria possível estabelecer uma hierarquia entre as cidades: 1) Princípio de Mercado: os bens e serviços são distribuídos em razão dos princípios econômicos da demanda e da oferta; 2) Princípio do Tráfego (ou dos Transportes): os bens e serviços são distribuídos segundo a localização entre os lugares centrais, e se dariam segundo 
a ótica da menor distância possível, para que seja feito o menor esforço de transporte possível para que tanto o consumidor demande como para o produtor ofertem; e 3) Princípio Administrativo (ou político-administrativo): a distribuição dos serviços tenderia a seguir a lógica político-administrativa (MONASTERIO; CALVACANTE, 2011).

Estes princípios orientariam, portanto, a maneira como os centros seriam distribuídos no modelo de lugares centrais para esta distribuição urbana. Em suma, a teoria dos lugares centrais apresenta a distribuição dos bens e serviços segundo sua localização, que depende hierarquicamente da influência exercida pelos centros urbanos, por natureza, fornecedores de bens e serviços dos mais variados possíveis, e quanto mais complexa for sua localização, ele tenderá aos estratos superiores da rede hierárquica. Estes bens e serviços, quanto mais complexos forem, seja pelos custos ou pelo preço, estariam localizados em áreas de abragências maiores (hierarquicamente superiores), em locais com demanda maiores, o que lhes permitiria ter rendimentos satisfatórios.

\subsection{TEORIA DA CAUSAÇÃO CIRCULAR E EFEITO DE ENCADEAMENTO}

O processo de desenvolvimento regional, independentemente dos fatores ou paradigmas em que se alicerça, não é uniforme em todos os lugares. Por sua vez, as regiões com maior capacidade de inovar e mais bem-dotadas de capital humano e de recursos naturais têm um desenvolvimento mais rápido, destacando-se como centros, e as restantes regiões, como periferia. Myrdal (1968), Perroux (1955; 1977), Hirschman (1958) e North (1977a; 1977b) destacam que há desequilíbrios crescentes entre regiões, e uma das alternativas para romper esse desequilíbrio e o ciclo vicioso é pela inovação, educação e pela base econômica.

Hirschman (1958) analisou as diferenças regionais considerando o investimento e o crescimento de algumas indústrias como resultado natural do crescimento econômico, pois os resultados da instalação de uma indústria não conseguem atingir todo o país. No entanto, seria natural que as regiões próximas dessas indústrias fossem mais desenvolvidas que as outras.

A indústria é, por muitos, considerada o setor dinâmico por excelência já que exerce fortes efeitos denominados linkages sobre as demais atividades. Hirschman (1958) descreveu o crescimento desequilibrado, encadeamentos para frente e para trás (backward and forward linkages), exercidos a jusante e a montante dessas atividades. A dinâmica pressupõe um estado de desequilíbrio, movimento e mudança, que fazem com que a economia cresça ao longo do tempo. Ela envolve a condição e o movimento de uma economia que está em processo de transformação. Essa transformação pode ser impulsionada pelo progresso e pelo avanço de um setor ou ramo de atividades por meio de sua capacidade de influenciar os outros. Isso pressupõe que o processo de desenvolvimento regional seja feito numa série de desequilíbrios (HISCHMAN, 1958).

Myrdal (1968) contestou os efeitos benéficos do crescimento polarizado, dizendo que os efeitos positivos são anulados pelos efeitos negativos. A atração dos recursos produtivos em favor do polo atuaria no sentido do desequilíbrio, favorecendo as regiões mais ricas em detrimento das mais pobres. É nesse contexto que Myrdal (1968) introduz o princípio da cumulatividade dos efeitos ou causas na concentração geográfica das atividades produtivas. Assim, a localização de uma nova atividade econômica tende a levar ao aumento do emprego e da população que, por sua vez, atrairia novas atividades se, entretanto, fosse formado um mercado consumidor. 
Matos (2000) comenta que a dinâmica do crescimento regional é analisada, muitas vezes, recorrendo às teorias e aos modelos explicativos derivados do corpo teórico mais geral da economia regional. Os modelos elaborados, muitas vezes, são levados para o todo nacional, ignorando, na maioria das vezes, as particularidades de cada região. Sabe-se que o crescimento equilibrado de toda economia nacional (formada por várias regiões) é extremamente difícil de atingir.

A abordagem cumulativa dos efeitos ou causas7 possibilitou a Myrdal (1968) integrar, de forma sistemática, os problemas de escolha ótima da localização com os problemas do desenvolvimento regional. Analisando a Figura 3, o modelo concebido para um país com baixo desenvolvimento econômico, que apresenta como a localização, num determinado local, de uma nova atividade econômica, com razoável dimensão, teria efeitos positivos na expansão do emprego e da população. Myrdal (1968) afirma que dotar a região com infraestrutura, empresas públicas, serviços básicos de educação e saúde resulta num aumento das receitas fiscais, o que leva a uma melhoria no ambiente empresarial na região/local. Essa teoria é, contudo, uma das poucas do desenvolvimento regional em que o sistema econômico é abordado de forma dinâmica.

A abordagem cumulativa dos efeitos ou causas envolve simultaneamente os problemas de localização e os da teoria do desenvolvimento regional. Ela parte do princípio de que a escolha da localização e o desenvolvimento econômico, na ótica regional e mundial, só podem ser explicados pela mobilidade espacial do capital (SANTOS, 1994; BECKER, 2000, 2010).

Figura 3 - Princípios das Causas Cumulativas

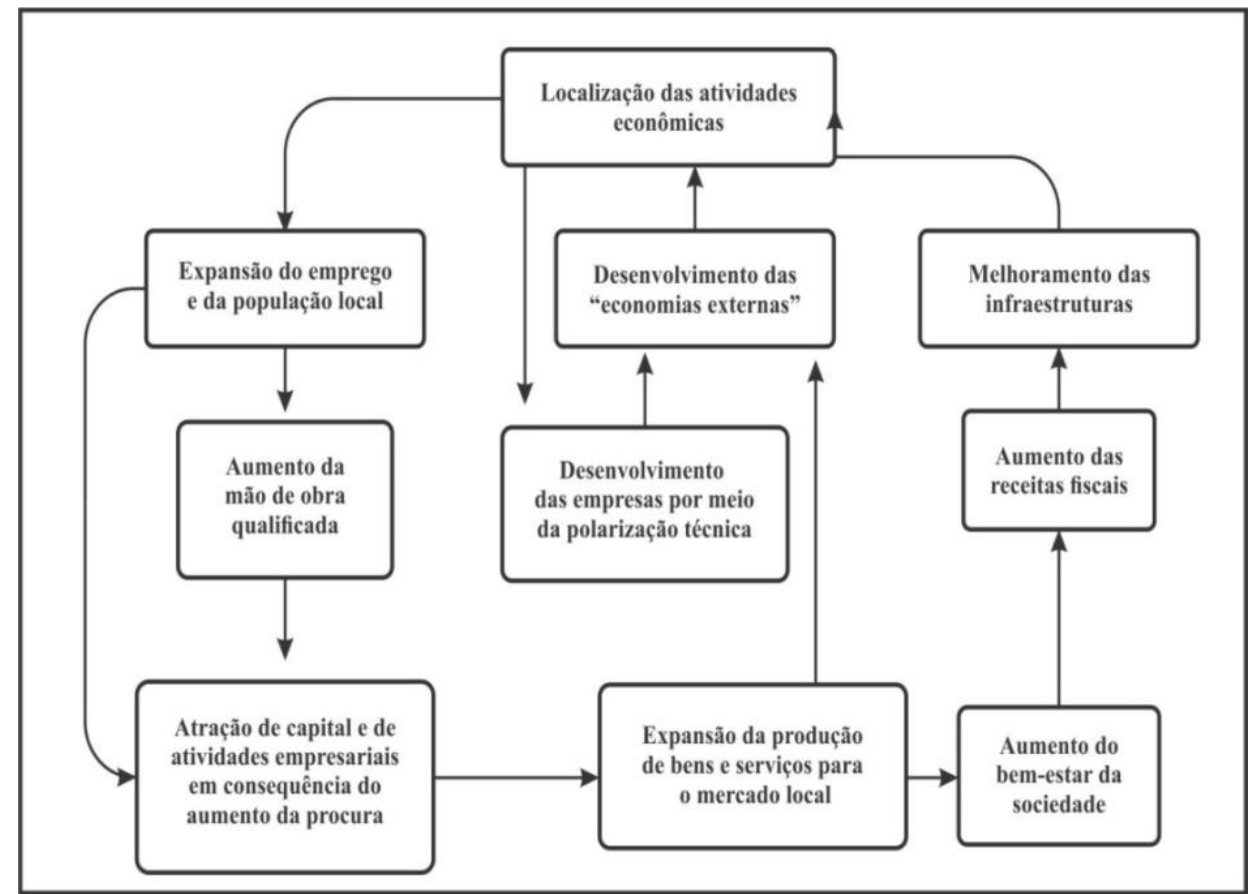

Fonte: Matos (2000) adaptado pelo autor.

\footnotetext{
7 Os efeitos e causa Myrdal chamou de spread e backwash. Os spreads effects são efeitos cumulativos inter-regionais positivos com origem na região e que se ramificam para o resto do país. Os backwash effects são efeitos cumulativos inter-regionais negativos que se ramificam para o resto do país em razão da atração dos fatores para a região.
} 
Certas regiões apresentam grandes desigualdades econômicas e sociais, ou seja, têm características que lhes permitem criar uma organização desigual do espaço, citando Matos (2000), ocorrem o poder dominante das grandes unidades (teorias dos polos de crescimento); o caráter cumulativo dos mecanismos de crescimento (teoria da causalidade circular de Myrdal); a lógica do capital (teoria do imperialismo); a ação das forças que retardam ou anulam a convergência (teoria centro-periferia); e as tendências de especialização hierarquizada dos espaços (teoria da divisão espacial do Trabalho). Assim, segundo Aydalot (1985), o espaço não é mais, como para os neoclássicos, um elemento a integrar, equalizar e uniformizar, mas, pelo contrário, ele é a base da desigualdade técnica, econômica e social.

As causas da construção de polos de desenvolvimento econômico estão ligadas a fatores naturais e de natureza política na construção desses espaços. Pela ótica das potencialidades, regiões economicamente dinâmicas são aquelas que dispõem de concentração de matérias-primas em diversas frentes de possibilidade de produção econômica. Nesse sentido, são áreas potencialmente dinâmicas que podem colaborar na promoção do desenvolvimento com o surgimento de políticas efetivas na construção de espaços econômicos integrados. Nessa ótica, as potencialidades se tornam efetivas diante do processo de construção econômica do espaço (PERROUX, 1955; MYRDAL, 1968; BOUDEVILLE, 1973).

Na concepção de Piffer et al. (2007), o desenvolvimento de uma região passa necessariamente pela análise das questões suscitadas pelas narrativas identitárias regionais e suas implicações com a chamada identidade cultural, naturalização da identidade frente à globalização. A região é o último recurso de estabilidade e de reconhecimento no desenvolvimento regional. Dessa forma, são necessárias a discussão e a análise da identidade regional sob a ótica da diferença, da alteridade (outro) e o estranho em um mundo globalizado marcado pela ordem hegemônica.

Faz-se importante ressaltar a afirmação de Piffer et al. (2007), destacando que o processo de desenvolvimento regional não deve ser realizado exclusivamente para o mercado, mas para a população e suas comunidades. Essa falta de interação entre o capital social não é boa para a região. O desenvolvimento deve ser visto como um processo endógeno movido pelo capital social e suas interações. Por meio da cooperação e da interação, as atividades econômicas podem ser estimuladas, as cadeias produtivas complementadas, novos sistemas produtivos criados e, com isso, induzir o desenvolvimento regional.

\subsection{A TEORIA DA BASE ECONÔMICA}

A Teoria da Base Econômica teve como pioneiro os trabalhos de North (1977a) para explicar como se dá o processo de desenvolvimento econômico via base econômica das atividades produtivas. Esse estudo é considerado o primeiro a dar uma formulação do conceito de base aplicado ao contexto regional. Esta teoria possibilita a forma mais simples de modelo de renda regional, sendo que sua importância está no fato de servir como estrutura teórica para estudos empíricos de regiões (RICHARDSON, 1975). A teoria da base econômica explica essas relações interregionais que envolvem o fluxo de mercadorias, de pessoas e de serviços, bem como avalia as implicações desses fluxos entre a região e o restante da economia mundial.

Schwartzman (1975) explica que o desenvolvimento de uma região depende do dinamismo da base econômica e da sua difusão para o resto da economia regional, ou seja, deve apresentar duas condições necessárias para o desenvolvimento: 1) manutenção do dinamismo do produto de exportação; e 2) difusão do dinamismo para outros setores da economica (Figura 4).

Informe GEPEC, ISSN:1679-415X, Toledo, v. 25, n.1, p. 203-219, jan./jun. 2021. 
A primeira condição é ter um crescimento da renda real de uma economia para ter desenvolvimento econômico. Sendo assim, é necessário que a venda dos produtos de exportação esteja crescendo a uma taxa expresiva para que sejam criadas na região condições necessárias ao desenvolvimento.

$\mathrm{Na}$ segunda condição, a difusão ocorre quando o produto de exportação desenvolve outros setores da economia, sendo necessário, para que isso aconteça, que surjam outras atividades produtivas, que a distribuição de renda atinja um número elevado de pessoas e que surjam outras bases de exportações.

Figura 4 - Fatores que condicionam a capacidade de uma região se desenvolver a partir de uma base econômica

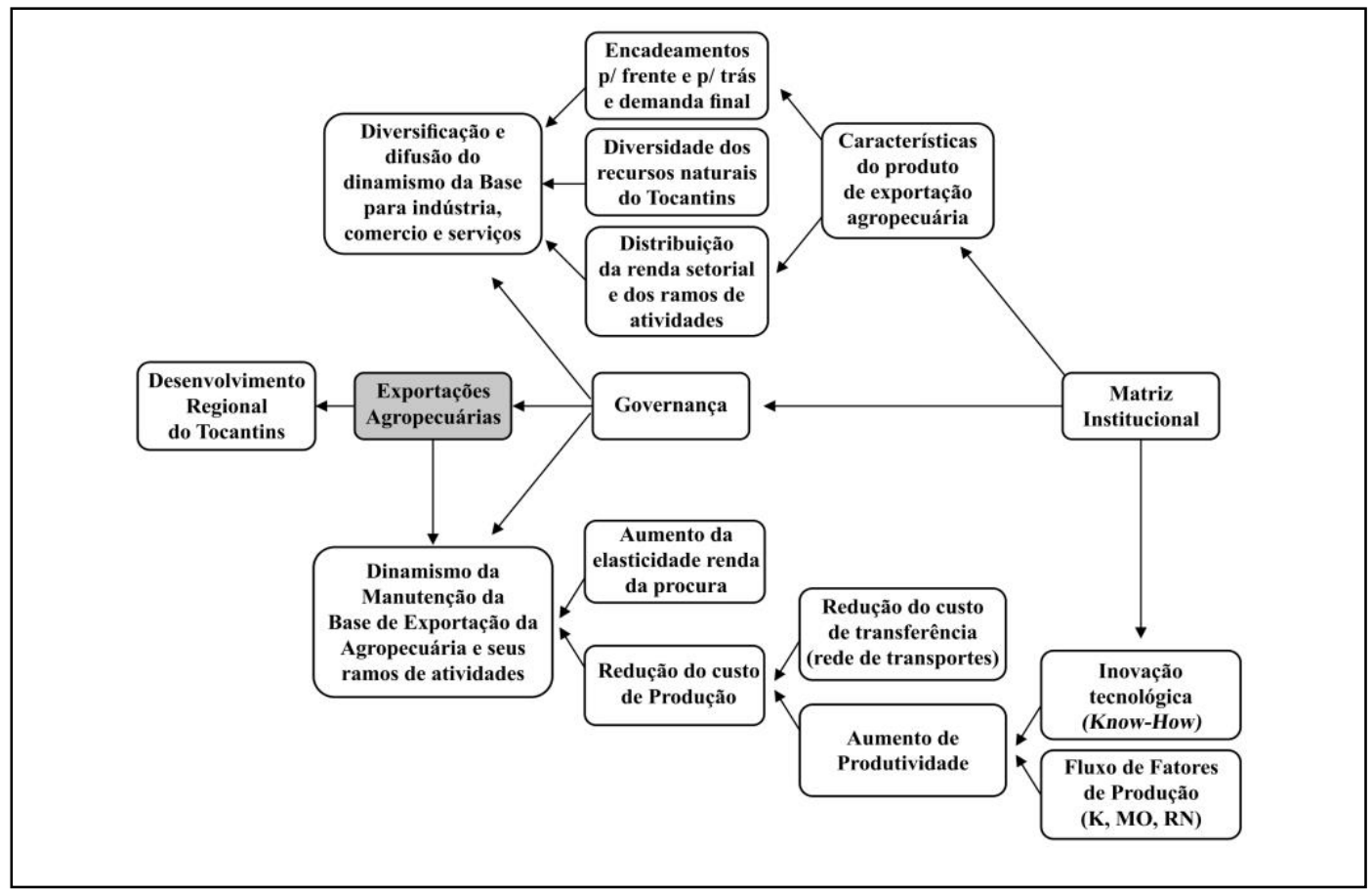

Fonte: Schwartzman, (1975), adaptado pelo autor.

Para manter o dinamismo dos produtos de exportação, dois fatores são importantes: 1) a elasticidade-renda da demanda, que determina a possibilidade de a região manter o seu dinamismo por meio de um só produto de exportação, ou seja, tendo o produto uma baixa elasticidade-renda, não haverá tendência para aumento de suas vendas à medida que as regiões importadoras se desenvolvem; 2) custo do produto de exportação, a redução do custo do produto fará com que haja aumento da sua capacidade competitiva, devendo, portanto, melhorar a rede de transporte e/ou o aumento da produtividade por meio dos fatores de produção.

Schwartzman (1975) também considera quatro variáveis estratégicas para o desenvolvimento regional:1) a propensão a importar contida na análise do multiplicador, a qual depende da função de produção do produto de exportação, da distribuição de renda e das características tecnológicas da base ao requerer mais ou menos insumos que podem ser produzidos na região a preços competitivos; 2) a propensão a consumir e a poupar, que também será influenciada pela função de produção, via distribuição de renda; 3) os custos de transferência; e 4) as variações na produtividade, que constituem os fatores que influenciam o custo de produção da base e são influenciadas pelas variações tecnológicas e pelos fluxos de fatores de produção escassos que a região consegue atrair. 
A atividade total de uma região apresenta uma dicotomia bastante nítida, constando, de um lado, as atividades básicas (exportação) e, do outro, as atividades locais (mercado interno). Na concepção de North (1977b), a região só se desenvolve a partir da sua base exportadora e dos arranjos institucionais para fortalecer essa base. As rendas geradas pela procura externa de bens e de serviços impulsionam as atividades locais e diminuem os custos de transação. Esse conceito de base econômica ou de exportação pode ser empregado para a análise tanto de regiões como de setores ou de ramos de atividades urbanas.

\section{CONSIDERAÇÕES FINAIS}

O objetivo deste ensaio foi revisitar os conceitos sobre desenvolvimento regional, que, como foi visto, constitui um processo de transformação social, econômica, cultural e política. Essas transformações são questões centrais para entender a evolução da dinâmica dos setores produtivos de uma região.

Neste sentido, a região e o processo de desenvolvimento que tomam o espaço não podem ser vistos como um substrato neutro, mas como uma expressão da realidade social, com sua particularidade histórica, seu pertencimento e sua identidade local. Deve-se reconhecer seu caráter histórico e mutável, pelo fato de que, em seu interior, vão sendo constituídos uma unidade econômica e um todo econômico orgânico que representa uma categoria separada, qualitativamente diferente das outras regiões. A região é, por consequência, forma e conteúdo. De uma só vez, um conjunto orgânico de relações sociais e uma porção do espaço construído são utilizados pela sociedade humana que o ocupa no seu processo de desenvolvimento regional.

Sobre as abordagens do conceito de desenvolvimento aqui discutido, pode-se observar a dificuldade de uma definição exata do termo desenvolvimento regional por abarcar uma dimensão no seu conceito, seja ela no processo de contradição, histórico e social. Alguns definem que o desenvolvimento regional é um processo histórico, desigual no tempo e no espaço; outros dizem que ele pode se apresentar de forma concentrada, formando os polos de crescimentos, pois a dinâmica de capital tende a atrair fatores de produção crescendo mais rapidamente, enquanto regiões com problemas estruturais perdem populações e capitais. Logo, o crescimento não surge em toda parte ao mesmo tempo, mas aparece com intensidades variáveis em pontos diferentes e se propaga no conjunto da economia, criando, assim, as chamadas desigualdades regionais. Nesta linha de pensamento, entra a discussão do planejamento como uma precondição de ações programadas no tempo em que se busca a identificação dos problemas, promovendo, desta forma, o desenvolvimento regional.

Enfim, o desenvolvimento regional de uma região ou local passa necessariamente pela análise das questões suscitadas pelas narrativas identitárias regionais e suas implicações com a chamada identidade cultural, naturalização da identidade frente à globalização, ou seja, o processo de desenvolvimento regional, independentemente dos fatores ou paradigmas em que se alicerça, não é uniforme em todos os lugares.

\section{AGRADECIMENTOS:}


"O presente trabalho foi realizado com apoio da Coordenação de Aperfeiçoamento de Pessoal de Nível Superior - Brasil (CAPES) - Código de Financiamento 001.

\section{REFERÊNCIAS}

ALMEIDA, Neuler André Soares; ARAÚJO, José Júlio César Nascimento;

RODRIGUES, Francisco Mendes. A teoria dos lugares centrais e sua aplicabilidade no Programa Zona Franca Verde no Amazonas. Redes, Santa Cruz, v. 14, n. 1, p.106120, jan./abr. 2009.

AYDALOT, Philippe. Économie régionale et urbaine. Paris: Econômica, 1985.

BECKER, Dinizar Fermiano. A Economia Política do (Des) envolvimento Regional Contemporâneo. In: BECKER, Dinizar Fermiano.; WITTMANN, Milton Luiz. (Orgs) Desenvolvimento Regional: abordagens interdisciplinares. 2. ed. Santa Cruz: Edunisc, 2010.

BECKER, Dinizar Fermiano. Necessidades e Finalidades dos Projetos Regionais de Desenvolvimento Local. In: BECKER, Dinizar Fermiano. BANDEIRA, Pedro Silveira. (Orgs.) Desenvolvimento Local-Regional: Determinantes e desafios contemporâneos, v. 1. Santa Cruz: Edunisc, 2000.

BOISIER, Sergio. Em busca do esquivo desenvolvimento regional: entre a caixa-preta e o projeto político. Revista de Planejamento e Políticas Públicas, Brasília, n. 13, p. 111-143, jun. 1996.

BOISIER, Sergio. Desarrollo (Local): ¿ de qué estamos hablando? In: BECKER, Dinizar Fermiano.; BANDEIRA, Pedro Silveira. (Orgs.) Desenvolvimento LocalRegional: Determinantes e desafios contemporâneos, v. 1. Santa Cruz: Edunisc, 2000.

BOUDEVILLE, Jacques Raoul. Os Espaços Econômicos. São Paulo: Saber Atual, 1973

BRANDÃO, Carlos Antônio. Teorias, estratégias e políticas regionais e urbanas recentes: anotações para uma agenda do desenvolvimento territorializado. Revista paranaense de desenvolvimento, Curitiba, n.107, p. 57-76, jul./dez. 2004.

CANTILLON, Richard. Essai sur la Nature du Commerce en General: Paris: INED, 1952 (Primeira edição: 1755)

CHRISTALLER, Walter. Central Places in Southern Germany. New Jersy: Englewood Cliffs, 1933. 27-83 p

FERRERA DE LIMA, Jandir. La Diffusion Spatiale du Développement

Économique Regional : L'analyse des composantes du changement spatial dans la région Sud du Brésil. Sarrebruck: Éditions universitaires européennes, v. 01, 2010. $179 \mathrm{p}$ 
FURTADO Celso. Desenvolvimento e subdesenvolvimento. Rio de Janeiro: Contraponto: Centro internacional Celso Furtado, 2009. $234 \mathrm{p}$

HIRSCHMAN, Albert. Otto. Interregional and International transmission of economic growth. In: The strategy of economic development. Tradução Rui Cesar dos Santos. New Haven, Yala University Press, 1958, 183-201 p

ISARD, Walter. Méthodes D’analise Régionale. Paris: Dunod, 1962.

LOPES, António Simões. Desenvolvimento Regional: problemática, teoria e modelos. Lisboa: Fundação Calouste Gulbenkian, 2. ed. 1984. 2-35 p

LIMA, Ana Carolina Cruz; SIMÕES, Rodrigo. Ferreira. Teorias Clássicas do desenvolvimento regional e suas implicações de política econômica: o caso do Brasil.

Revista de Desenvolvimento Econômico, Salvador, ano XII, n. 21, p. 5-19, 2010.

MARSHALL, Alfred. Princípios de economia. São Paulo: Abril cultural, 1982. 2v. (Os economistas; Primeira edição: 1890).

MATOS, António de Jesus Fernandes de. Ordenamento territorial e desenvolvimento regional. 2000. 408p. Tese (Doutorado em Economia) Universidade da Beira Interior, Covilhã. 2000.

MONASTERIO, Leonardo; CAVALCANTE, Luís Ricardo. Fundamentos do Pensamento Econômico Regional. In: CRUZ, Bruno Oliveira; FURTADO, Bernardo Alves; MONASTERIO, Leonardo; RODRIGUES JUNIOR, Waldecy. (Orgs.).

Economia Regional e Urbana: teorias e métodos com ênfase no Brasil. Brasília: IPEA, 2011. 43-77 p

MYRDAL, Gunnar. Teoria econômica e regiões subdesenvolvidas. 2. ed. Rio de Janeiro: Saga, 1968.

NETTO, Henrique Fonseca. Considerações sobre as manifestações territoriais como paradigmas do desenvolvimento regional: da teoria a prática. Informe Gepec, Toledo, v.15, n.1, p.147-163, jan./jun.2011.

NORTH, Douglass Cecil. A agricultura no crescimento econômico. In: SCHWARTZMAN, Jacques. (Org.). Economia regional: textos escolhidos. Belo Horizonte, MG: CEDEPLAR/CETEDRE -MINTER, 1977a. 333-343 p

NORTH, Douglass Cecil. Teoria da localização e crescimento regional. In: SCHWARTZMAN, Jacques. (Org.) Economia regional: textos escolhidos. Belo Horizonte, MG: CEDEPLAR/CETEDRE -MINTER, 1977b. 291-314 p

OLIVEIRA, Nilton Marques; BRITO, Eliseu Pereira; MEDEIROS, Messias Rodrigues. Universidade Federal do Tocantins e sua inserção regional: uma abordagem da teoria dos lugares centrais. Interface, n. 6, maio, 2013.

OLIVEIRA, Nilton Marques. Desenvolvimento Regional do território do estado do Tocantins. Palmas-TO: EDUFT, 2019. $214 \mathrm{p}$ 
PERROUX, François. Note sur la notion de póle de croissance. Tradução com permissão da Revista Brasileira de Estudos Políticos. Economie appliquée, 1955 .

PERROUX, François. O Conceito de Polos de Crescimento. In: SCHWARTZMAN, Jacques. (Org.). Economia Regional: Textos Escolhidos. Belo Horizonte, CEDEPLAR, 1977.

PIFFER, Moacir.; ALVES, Lucir Ribeiro; FERRERA DE LIMA, Jandir. CAVALHEIRO Maria Eloísa; SILVA, Marizete Gonçalves. Desenvolvimento regional do Oeste Paranaense a partir do capital social. [s.1.], 2007. Disponível em: < http://files.luciralves.com/200000058831f4841c7/Desenvolvimento\%20regional\%2 odo\%20Oeste\%20Paranaense\%20a\%20partir\%20do\%20capital\%20social.pdf.

Acesso em: 20 out. 2020.

REIGADO, Felisberto Marques. Desenvolvimento e planejamento regional Uma Abordagem Sistémica. Lisboa: Editorial Estampa, 2000.

RICHARDSON, Harry. Economia regional: teoria da localização, estrutura urbana e crescimento regional. Rio de Janeiro: Zahar, 1975. 421p

SANTOS, Milton. Território: Globalização e fragmentação. São Paulo: Hucitec/ANPUR, 1994.

SCHWARTZMAN, Jacques. A teoria da base de exportação e o desenvolvimento regional. In: HADDAD, Paulo R. Desequilíbrios regionais e descentralização industrial. Rio de Janeiro: IPEA/INPES, 1975.

STÖHR, Walter B. Development from below: the bottom-up and periphery - inward development paradigm. In: STÖHR, Walter; FRASER, Taylor. (Org). Development from above or below? The Dialectics of Regional Planning in Developing Countries. J. Wiley \& Sons, Ltd, Chischester, 1981.

von THÜNEN, Johann Heinrich. The Isolated State. New York: Pergamon Press, 1966. (Primeira edição: 1826).

Sobre o Autor:

Submetido em $7 / 8 / 2020$ Aprovado em 20/12/2O2O

Nilton Marques Oliveira

Economista pela UEM, Mestre em Economia Aplicada pela UFV e Doutor em Desenvolvimento Regional e Agronegócio pela UNIOESTE, Toledo - PR. Professor do Programa de Pós-graduação em Desenvolvimento Regional e do curso de Ciências Econômica da Universidade Federal do Tocantins UFT. Líder do Grupo de Pesquisa em Desenvolvimento Regional e Territorial do Centro Norte do Brasil (DRT - Centro Norte). Email: niltonmarques@uft.edu.br 